\title{
An introduction to the Knowledge Translation special issue of the Canadian Respiratory Journal
}

\author{
Samir Gupta MD FRCPC ${ }^{1}$, Pat G Camp BSc(PT) PhD²,3
}

$\mathrm{H}$ ealth sciences research continues to progress at an astounding pace, with the discovery of novel molecules, therapies and technologies to yield ever newer health-related knowledge. Yet, despite the time and resources devoted to identify these myriad new ways to improve health, evaluations of actual care consistently demonstrate gaps between this medical knowledge ('what we ought to be doing') and its application in practice ('what we are doing') (1). The obvious implication is that our patients are not reaping the full benefits of advances in medical knowledge. Accordingly, organizations around the world are increasingly recognizing the danger of investment in knowledge creation without complementary investment in knowledge implementation. This paradigm shift has given rise to the science of knowledge translation (KT).

\section{What is KT? \\ The Canadian Institutes of Health Research (CIHR) defines KT as "a dynamic and iterative process that includes synthesis, dissemination, exchange and ethically-sound application of knowledge to improve the health of Canadians, provide more effective health services and products and strengthen the health care system" (2). More simply, KT is the act of closing the knowledge-to-practice gap, or the so-called 'know-do' gap. It subsumes all activities that occur after knowledge is created, including analysis of the magnitude of care gaps and barriers and facilitators to application of knowledge, development of strategies to overcome barriers and to utilize facilitators, and objective measure- ments of the success of these strategies and their sustainability (3).}

\section{The Knowledge-to-Action cycle}

Successful KT requires an ability to comprehend a complex social system comprised of individuals and groups of individuals to influence their behaviour (so-called 'planned-action') (4). Accordingly, theoretical frameworks for KT have largely been built on existing principles of organizational innovation, and social and behavioural psychology (4). In 2006, Graham et al (3) undertook a review of more than 60 such planned-action theories, frameworks and models, identifying common elements in an effort to develop a practical model for KT activities. This model, known as the 'Knowledge-to-Action' (KTA) process, is a multistep systematic process that guides the planning, design, execution and evaluation of KT activities. It has since been adopted by the CIHR as their conceptual framework for KT activities, and has gained wide adoption in both Canada and abroad (2). Accordingly, it has been applied and cited in a number of the Canadian KT initiatives presented herein.

Whence this KT supplement to the Canadian Respiratory Journal? $\mathrm{KT}$ remains a relatively young science and, as in all health areas, the need for KT in respiratory illness is urgent. The goal of the present KT supplement is multifold, including: educating Canadian health care practitioners involved in respiratory disease care about the meaning and importance of KT, thereby also sparking an interest among Canadian practitioners and researchers in KT work; and showcasing the growing expertise and successes in KT in the field of respiratory medicine across Canada.
The supplement progresses from general concepts to specific studies. It begins with an introduction to the Canadian Thoracic Society's (CTS) new Framework for KT activities, which will now complement all CTS guidelines. Next, Boulet et al (pages 265-269) present a narrative review discussing some of the key care gaps in common respiratory diseases (asthma, chronic obstructive pulmonary disease [COPD], and obstructive sleep apnea), where KT is sorely required. Hoens et al (pages 271-274) then demonstrate the role and potential of knowledge brokers in the KT process, and Boulet et al (pages 275-280) follow with important lessons learned when an ambitious national study of asthma and COPD guideline implementation in primary care was terminated due to failed recruitment. Camp et al (pages 281-284) then present the rationale and methods for a novel KT study aiming to implement evidence-based exercise for patients hospitalized with acute exacerbation of COPD, and J Lamontagne et al (pages 285-293) report the results of a qualitative study that identified solutions to encourage physicians to prescribe appropriate asthma management regimens. Douglas et al (pages 295-300) follow with a systematic application of the KTA process in the implementation of an asthma education program for First Nations children. Finally, Licskai et al (pages 301-306) present outcomes from a pilot study of a novel smartphone application for patients with asthma, aiming to implement guidelinerecommended collaborative self-management.

We are certain that you will agree these examples provide an exciting snapshot of what we believe is a growing interest in KT related to respiratory care in Canada. As a respiratory community, we should no longer be comfortable with the status quo - knowledge dissemination limited to poster presentations and published articles. The articles in the current supplement highlight the type of work that must be performed to enable change in practice for our patients to benefit from new knowledge. As KT capacity builds and successes multiply, the future can only be brighter for all Canadians suffering from respiratory illness.

DISCLOSURES: The authors have no finacial disclosures or conflicts of interest to declare.

\section{REFERENCES}

1. McGlynn EA, Asch SM, Adams J, et al. The quality of health care delivered to adults in the United States. N Engl J Med 2003;348:2635-45

2. Canadian Institutes of Health Research. More About Knowledge Translation at CIHR. <www.cihr-irsc.gc.ca/e/39033.html> (Accessed March 12, 2013).

3. Graham ID, Logan J, Harrison MB, et al. Lost in knowledge translation: Time for a map? J Contin Educ Health Profess 2006;26:13-24.

4. Estabrooks CA, Thompson DS, Lovely JJE, Hofmeyer A. A guide to knowledge translation theory. J Contin Educ Health Profess 2006;26:25-36.

\footnotetext{
${ }^{1}$ The Keenan Research Centre in the Li Ka Shing Knowledge Institute of St Michael's Hospital, University of Toronto Department of Medicine, Canada (Institution from where the work originated), Toronto, Ontario; ${ }^{2}$ James Hogg Research Centre, St Paul's Hospital; $3{ }^{3}$ Department of Physical Therapy, University of British Columbia, Vancouver, British Columbia

Correspondence: Dr Samir Gupta, The Keenan Research Centre in the Li Ka Shing Knowledge Institute of St Michael's Hospital, Suite 6044, Bond Wing, 30 Bond Street, Toronto, Ontario M5B 1W8. Telephone 416-864-6060 ext 2252, fax 416-864-5649,

e-mail guptas@smh.ca
} 


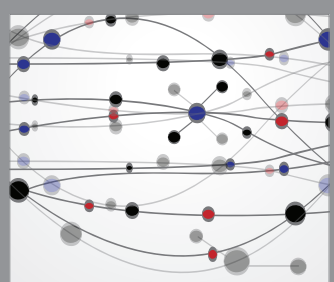

The Scientific World Journal
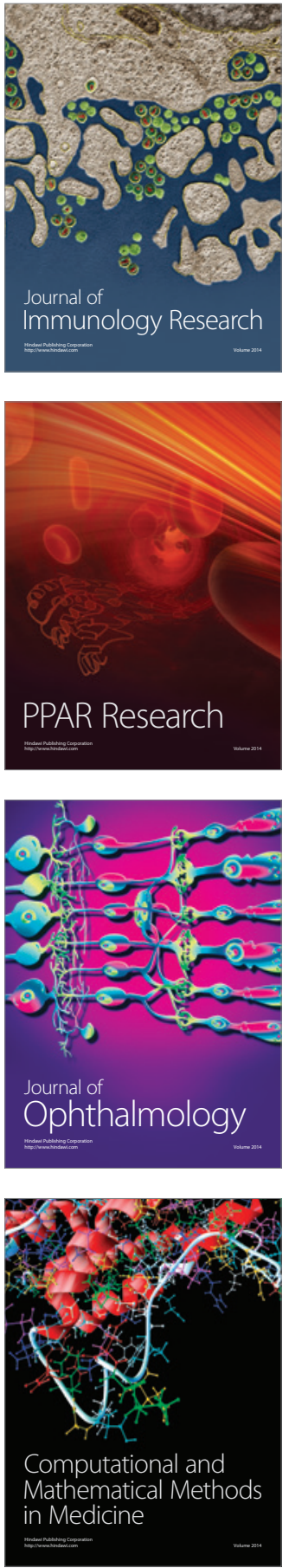

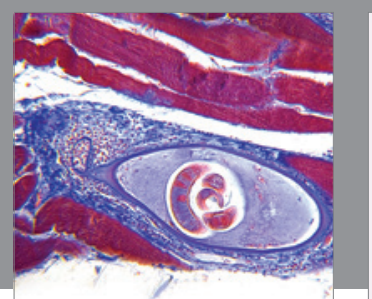

Gastroenterology Research and Practice

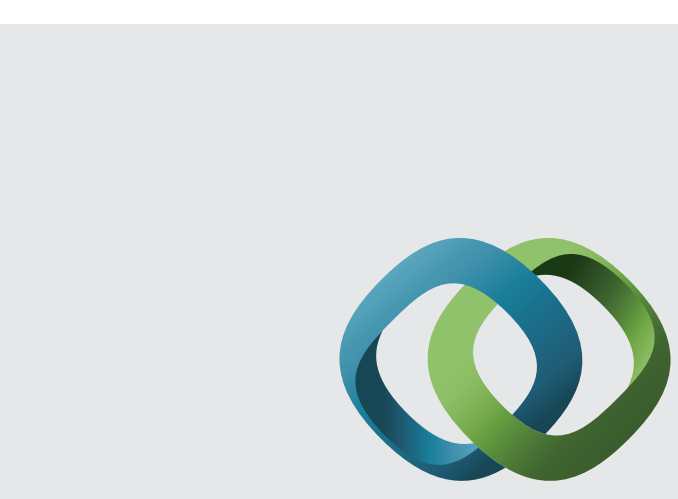

\section{Hindawi}

Submit your manuscripts at

http://www.hindawi.com
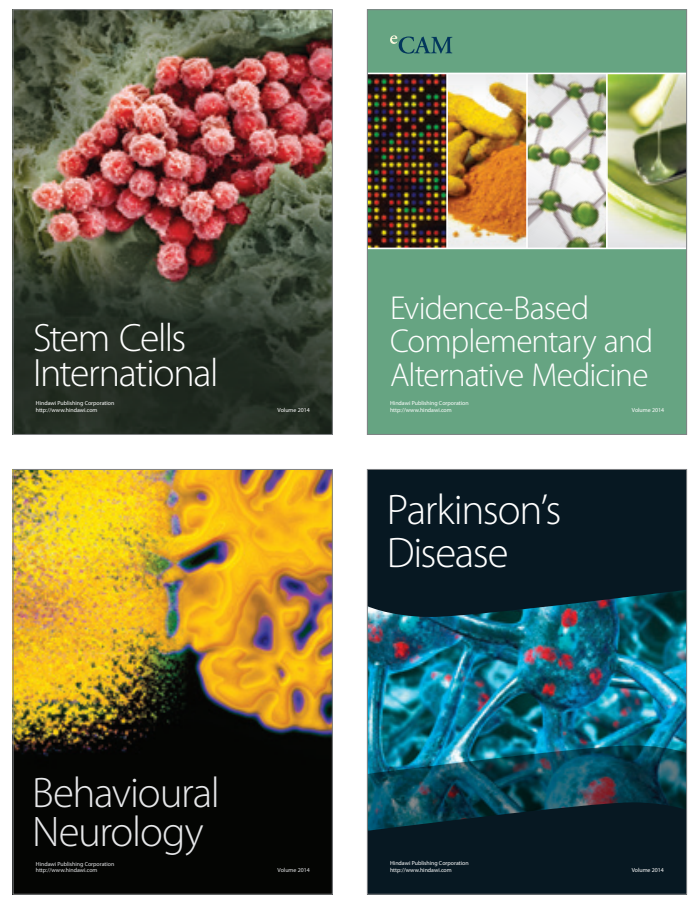
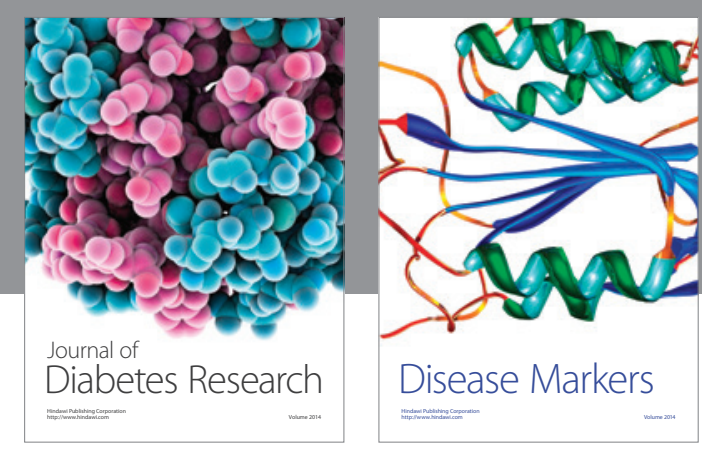

Disease Markers
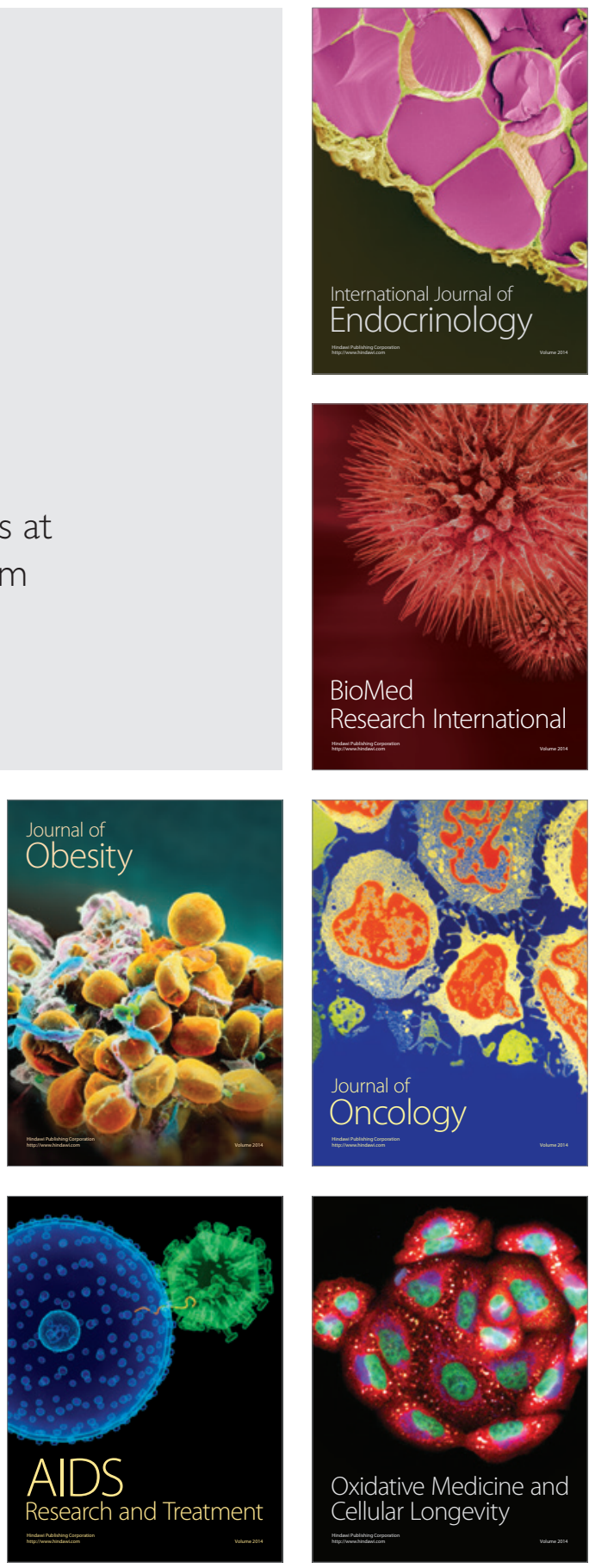